ache. ${ }^{2}$ Bed rest was commonly practised despite having no value in the prevention of headache. ${ }^{5}$

Treatment of established headache after lumbar puncture includes hydration, analgesics, vasopressin, and caffeine. More invasive techniques include the installation of saline or autologous blood into the epidural space. The latter procedure (epidural blood patching) has a success rate of $90 \%$ with only minor short term sequelae. Very few of the departments in our study said that they would consider this option within the first 72 hours, although early use is strongly advocated in anaesthetic circles. This may be because other causes of the headache are more likely or because the patient has a fever, which precludes blood patching. However, epidural blood patching would be considered by a good proportion of neurologists after 72 hours.

We thank all those who took the time and effort to respond to our questionnaire.
Contributors: MGS and DC initiated the research. MGS participated in the study design, data collection, analysis, interpretation, and writing of the paper and will act as guarantor. GJH participated in data collection, analysis, interpretation, and writing of the paper. DRSJ participated in the study design and the interpretation and, together with DC, edited the paper.

Funding: None.

Conflict of interest: None.

1 Tourtellotte WW, Henderson WG, Tucker RP, Gilland O, Walker JE, Kokman E. A randomised, double blind clinical trial comparing the 22 versu 26 gauge needle in the production of the post-lumbar puncture syndrome in normal individuals. Headache 1972;12:73-8.

2 Carson D, Serpell M. Choosing the best needle for diagnostic lumbar puncture. Neurology 1996;47:33-7.

3 Mihic DN. Postspinal headache, needle surface and longitudinal orientation of the dural fibres. Results of a survey. Reg Anesth 1986;9:54-6.

4 Kuntz KM, Kohmen E, Stevens JC, Miller P, Offord KP, Ho MM. Post-lumbar puncture headaches: experience in 501 consecutive procedures. Neurology 1992;42:1884-7.

5 Carbaat PAT, VanCrevel H. Lumbar puncture headache. Controlled study in the preventive effect of 24 hours bed rest. Lancet 1981;ii:1133-5. (Accepted 3 December 1997)

\title{
Problems in retrieving national data on births: questionnaire survey
}

\author{
Lesley Smith
}

King's Fund, London W1M 0AN Lesley Smith, researcher for CESDI colls@kehf.org.uk

BMJ 1998;316:1710-1
Although more data on maternal and child health are being collected locally, the amount of data available nationally has fallen over the past decade. ${ }^{1}$ Central sources of data exist in England and Wales, but clinical data are limited (Office for National Statistics registrations) or of poor quality (maternity hospital episode system, patient episode data Wales). ${ }^{2}$ Only Northern Ireland (child health record system) and Scotland (Scottish Morbidity Record-SMR2) provide good quality data on maternal and child health. ${ }^{3}$

If national data were available, trends in health care as well as morbidity and mortality for rare conditions could be analysed. National data would also be useful to the confidential inquiry into stillbirths and deaths in infancy (CESDI)-the survey that covers fetal and infant deaths between 20 weeks' gestation and 1 year in England, Wales, and Northern Ireland. The numerator data collected through the survey's rapid reporting process cannot be interpreted without national

Difficulties met by regional coordinators in generating regional data for 1993 and 1995 . Values are numbers of difficulties mentioned by coordinators

\begin{tabular}{lcc} 
Difficulties & $\begin{array}{c}\mathbf{1 9 9 3} \text { data } \\
(\mathbf{n = 1 5 )}\end{array}$ & $\begin{array}{c}\mathbf{1 9 9 5} \text { data } \\
\mathbf{( n = 1 3 )}\end{array}$ \\
\hline No central point covering region & 7 & $9^{*}$ \\
\hline Data were hospital based & 4 & $4 \dagger$ \\
\hline Quality of data in doubt & 4 & $3^{\star}$ \\
\hline Data aggregated or defined differently from confidential inquiry data & 3 & 3 \\
\hline Low priority given to providing regional data & 0 & 3 \\
\hline Lack of staff & 2 & 3 \\
\hline Data not totalled & 2 & $2^{\star}$ \\
\hline Incompatible, non-uniform information systems & 1 & $2^{*}$ \\
\hline Technical problems & 1 & 1 \\
\hline Fee requested & 1 & $?$ \\
\hline Data no longer available or available too late & 1 & 1 \\
\hline Data not available for research & 0 & 1 \\
\hline
\end{tabular}

*In one case, other sources indicate that difficulty still exists, but was not specifically mentioned by the coordinator in the 1996 survey.

†In all cases the difficulty still exists but was not specifically mentioned. denominator data. In recognition of this need, a study was carried out to determine whether population based data for 1993 and 1995 could be obtained from regional sources.

\section{Methods and results}

In 1993, as part of a study managed by the National Perinatal Epidemiology Unit, all district and regional public health departments were asked for information on sources of maternity and child health data. Systems for collecting either maternity or child health data were in place in almost every district. Six regions in England, Wales, and Northern Ireland operated uniform systems across former regional health authorities; five had a procedure or independent survey; and three had so many different systems that it would have been impossible to retrieve regional data.

In September 1994, all 16 regional coordinators for the confidential inquiry into stillbirths and deaths in infancy were sent a list of 22 data items and asked to identify those available from NHS sources for all babies delivered in 1993 to residents in their region. Fifteen lists were returned, and four common variables of gestation, time of delivery, parity, and onset of labour were chosen.

In January 1995, a form requesting population based aggregated 1993 data for the chosen variables (with clear definitions) was sent to nine regional coordinators. All were confident of producing results since similar data had been generated for their own reports. Four of the nine regions produced all the data requested. One region supplied half the data, which were hospital based and therefore unusable, and three regions could not generate any data.

In June 1996, 16 regional coordinators were sent a follow up questionnaire on 1995 data. Three did not respond-two did not wish to and one had not partici- 
pated in the first survey. Of the 13 respondents, 11 of whom had returned the previous survey, only two commented that population based data could be produced, while another two could supply hospital based datasets. The obstacles encountered by regional coordinators in providing data for 1993 and 1995 are given in the table.

\section{Comment}

Obtaining comparable national data on births from NHS sources is difficult for even the most basic items, and the situation is worsening rapidly. Undoubtedly, the loss of the information gathering function of former regional health authorities has had an important impact. However, a few coordinators mentioned a new factor: contributing to national data had a low priority. They blamed purchasers and the Department of Health, but many doctors also show little interest. ${ }^{4}$

If we are to have national data on births, risks and benefits will have to be identified for the NHS Executive, the Department of Health, purchasers, doctors, midwives, and data entry clerks. Once these groups are convinced of the importance of this work, a coalition of committed participants could be formed to resolve the difficulties illustrated by this study.

A recent study showed that only $60 \%$ of midwives could retrieve useful information from local maternity systems, while those working regionally and nationally find data almost unobtainable. ${ }^{5}$ With such an imbalance between the high effort to input data and the low utility of output, is collecting dozens of details for every birth worthwhile?

Many thanks to Alison Macfarlane (National Perinatal Epidemiology Unit), Lesz Lancucki (Department of Health) and the staff of the secretariat of the confidential inquiry into stillbirths and deaths in infancy, in particular Verena Wallace, Juliet McEachran, and past directors Ralph Settatree and Rosalind Stanwell Smith. A special thanks to all the regional coordinators who put in extra time and effort to make this study possible.

A full report is available from the Confidential Enquiry into Stillbirths and Deaths in Infancy Secretariat, Chiltern Court, 188 Baker Street, London NW1 5SD.

Funding: Confidential Enquiry into Stillbirths and Deaths in Infancy Secretariat.

Conflict of interest: None.

1 Macfarlane A, Mugford M, Johnson A, Garcia J. Counting the changes in childbirth: trends and gaps in national statistics. Oxford: National Perinatal Epidemiology Unit, 1995

2 Middle C, Macfarlane A. Labour and delivery in 'normal' primiparous women-analysis of routine collected data. Report for the Clinical Standard Advisory Group. Oxford: National Perinatal Epidemiology Unit, 1995.

3 Department of Health. Annual report on confidential enquiries into stillbirths and deaths in infancy 1994. London: HMSO, 1996.

4 NHS Executive. HISS management of change-removing the barriers to clinicians' acceptance of HISS. A study of the communication links in an obstetric unit. Winchester: Hospital Information Support Systems, 1996 (Report D4039.)

5 Dobson P. Survey of computerised midwifery information systems. $\mathrm{Br}$ Midwifery 1995;3:487-92.

(Accepted 21 November 1997)

\title{
Abortion rates in England in 1995: comparative study of data from district health authorities
}

\author{
Veena Soni Raleigh
}

British developmental aid for developing countries prioritises greater reproductive choice for women through improved contraceptive services. But is enough being done in the United Kingdom to reduce unwanted pregnancies? I studied lifetime fertility, abortion rates, and the proportion of pregnancies resulting in induced abortion in 105 district health authorities in England.

\section{Subjects, methods, and results}

I analysed data on births and legal abortions during 1995 by district health authority as compiled by the Office for National Statistics. Total period fertility rates are a conventional measure of the mean number of live births that a woman would have if she experienced the current age specific fertility rates throughout her childbearing years. These rates were calculated by summing the 5 year age specific fertility rates at ages 15-49 and multiplying by 5 . Total period abortion rates were similarly calculated. The total period pregnancy rate is the sum of the total period abortion rate and total period fertility rate. Stillbirths and spontaneous abortions were excluded.

In 1995, 147851 abortions occurred among women resident in England compared with 613257

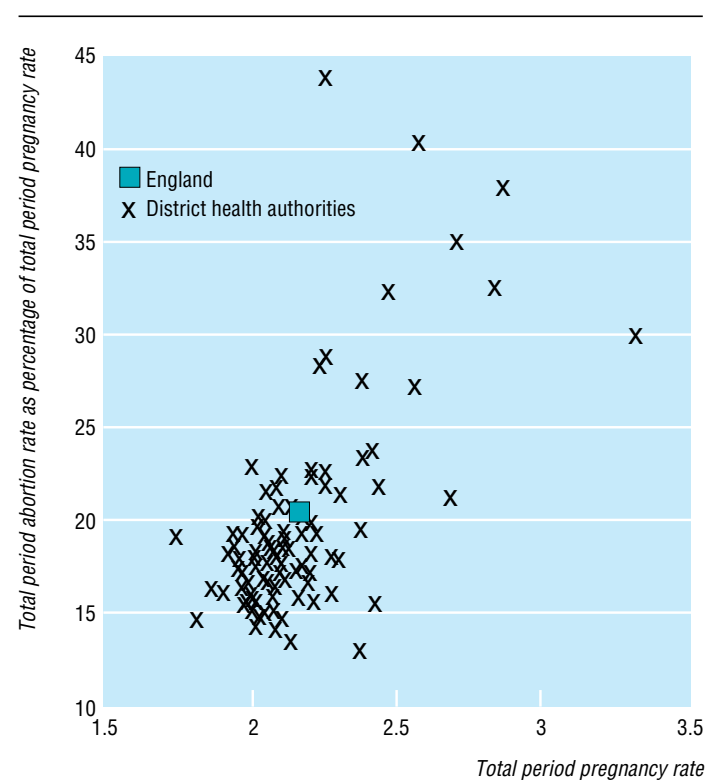

Total period pregnancy rates and total period abortion rates as percentages of total period pregnancy rates in England overall and by district health authority, 1995 